DOI: 10.15503/onis2011-321-328

\title{
Diabee w kazaniach Peregryna z Opola
}

\author{
Marcin Kiębus \\ marcin.kielbus@gmail.com
}

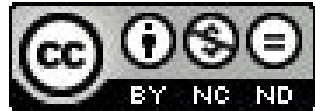

Nie od razu piekło zbudowano. Jego pozornie prosta konstrukcja z czasem rozbijała się o coraz bardziej zaawansowane szczegóły techniczne. Obok wybitnych specjalistów, trudniła się tym cała rzesza bezimiennych budowniczych. Mimo to pod koniec XIII wieku obiekt był daleki od ukończenia, więc piszący w tym czasie Peregryn z Opola mógł pokusić się o własny projekt lub przynajmniej jakąś korektę istniejących, ale nic takiego nie nastąpiło i jego kazania zatrzymały się na kopiowaniu. W ten sposób powstała pewna „piekielna synteza”, a zarazem próbka popularnej dydaktyki Kościoła.

Warto przypomnieć, że Pismo Św. na temat pośmiertnych losów człowieka wypowiada się mgliście i lakonicznie, a z tych nielicznych wzmianek jeszcze mniej można dowiedzieć się o piekle. Właściwie wszystko, co dziś o nim wiadomo, zostało stworzone tylko przy niewielkim udziale Biblii ${ }^{1}$. Znacznie od niej młodsi budowniczowie piekła mieli do dyspozycji głównie swoją wyobraźnię. Wobec czego ich idee są nie tylko niespójne, bo podejmujące różne zagadnienia $\mathrm{w}$ oderwaniu od siebie, ale z tego samego powodu też dość powikłane. Materię tę ogarnął i uporządkował Georges Minois w słynnej Historii piekła, a rezultaty tej pracy możemy odnieść do twórczości Peregryna z Opola. Ta zaś, jak się okazuje, zawiera wiele problemów istotnych dla tradycji, bo kaznodzieja ten szeroko rozpisywał się na temat piekła zarówno w zbiorze de tempore jak i de sanctis. Tym samym dołączyłby on do nurtu tzw. „duszpasterstwa strachu”, do którego przynależeli tacy kaznodzieje jak: Wincenty Ferrer, Hieronim Savonarola, czy Marcin Luter. Dołączyłby, gdyby nie pewna kwestia.

Jak pisze Minois: „Około roku 1250 teoretycznym usystematyzowaniem duszpasterstwa strachu zajmie się dominikanin Etienne de Bourbon. Poświęci on znaczną część swojej Rozprawy o kaznodziejstwie »darowi wzbudzania lęku« rozpatrywanemu pod kątem dziesięciu poszczególnych aspektów: 1. O siedmiu rodzajach strachu; 2. O tym, co może sprawiać lęk przed Bogiem; 3. O tym, iż należy bać się Boga; 4. O tym, iż należy bać się piekła; 5 . O tym, iż należy bać się piekła w życiu przyszłym; 6. O strachu przed Sądem Ostatecznym; 7. O strachu przed śmiercia; 8. O strachu przed grzechem; 9 . O tym, iż należy lękać się zguby już w życiu ziemskim; 10 . O naturze nieprzyjaciela rodzaju ludzkiego"2. Wszystkie te punkty w jakimś stopniu są poruszone w kazaniach Peregryna z Opola. Zwróćmy jednak uwagę, że inny znawca kultury i mentalności, Jean Delumeau, uznaje zjawiska trzynastowieczne i starsze tylko za zapowiedź, natomiast „począwszy od XIV wieku - jak pisze - wszystko się zmienia, atmosfera staje się ciężka i to zepchnięcie na dalszy plan spraw diabelskich, które powiodło się klasycznemu wiekowi katedr, ustępuje pola stopniowej inwazji demonicznej. Boska komedia (której autor zmarł w 1321 r.) zaznacza symbolicznie to przejście z jednej epoki do innej oraz moment, począwszy od którego świadomość religijna zachodniej elity przestaje na długi czas stawiać opór fali satanizmu. Przyjdzie do siebie dopiero w XVII wieku”3.3. Tymczasem u Minoisa możemy znaleźć ukrytą polemikę, gdy pisze

1 G. Minois, Historia piekła, Warszawa 1996, s. 72- 75. A. Szyjewski, M. Sacha-Piekło, Piekło [w:] M. Sacha- Piekło (red.), Zaświaty i krainy mityczne. Leksykon, Kraków 1999.

2 G. Minois, Historia..., dz. cyt., s. 161.

3 J. Delumeau, Strach w kuturze Zachodu. XIV- XVIII w., Warszawa 1986, s. 221. 
on: „Kaznodzieje nie czekali na wiek XVII z duszpasterstwem strachu. Posługiwali się nim już od XII wieku, a szczególnie chętnie czynili to mnisi" ${ }^{\prime \prime}$. Widzimy tu jawną niezgodę z poglądem Delumeau, który z kolei dobitnie stwierdza: „Teolodzy XIII wieku odmówili wszelkiej pobłażliwości dla tych koszmarnych obrazów. Natomiast w epoce następnej przełamują one wszystkie zapory"5. Widzimy też, że w obu ujęciach XIII wiek odgrywa istotną rolę: u Delumeau jest to podgłębie późniejszych zjawisk, podczas gdy u Minoisa - to wiek eskalacji. Przyjrzyjmy się zatem powstającym u jego schyłku kazaniom Peregryna z Opola.

Interesujące nas tu zagadnienie jest $\mathrm{w}$ twórczości tego autora w przewadze rozproszone. $\mathrm{Na}$ tym tle ze względu na szersze potraktowanie tematu piekła lub demonologii należy wyróżnić kazanie: Na czwarta niedziele Adwentu [T 4] ${ }^{6}$, Na trzecia niedziele po Objawieniu Pańskim [T 12], Na druga niedziele po Wielkanocy [T 30], Na szósta niedziele po Zestaniu Ducha Świętego [T 46], Na szesnasta niedziele po Zestaniu Ducha Świętego [T 56], Na dwudziesta czwarta niedzielę po Zestaniu Ducha Świętego [T 64], Na święto Podwyższenia Krzyża Świętego [S 48] oraz Na Dzień Zaduszny [S 58].

Z kolei pierwszym merytorycznym problemem jest lokalizacja piekła. Peregryn usytuował je bezpośrednio pod ziemią i zgodny pozostał tu z narzucającą się etymologią pojęcia infernum. Co prawda termin ten oznacza „piec", ale infer oznacza „to, co jest niżej”, „na dole”, „podziemie”". Trzeba jednak odnotować, że w czasach Peregryna lokalizacja piekła nie jest warunkiem sine qua non, ale wariantem. Inaczej mówiąc, wcale nie jest prawda, że skoro już piekło jest, to musi zarazem g d z i e ś być w namacalny sposób. Jak pisze Georges Minois: „NNa przełomie IV i V wieku nic nie jest przesądzone ostatecznie prócz samego faktu istnienia piekła. [...] Ojcowie Kościoła dostarczyli tu pierwszego szkicu odpowiedzi, niezupełnie jeszcze precyzyjnych i czasami sprzecznych. W dużym uproszczeniu można tam wyróżnić prąd bardziej pobłażliwy, alegoryczny i uniwersalistyczny, oraz prąd rygorystyczny, realistyczny i selektywny, bliższy koncepcjom ludowym" ${ }^{\prime \prime}$. W tym podziale piekło umiejscowione pod ziemią to wytwór wyobraźni ludowej ale, jak wiemy, XIII stulecie to czas spekulacji scholastycznej. Jak to klarownie przedstawia Minois: „,Piekło ludowe kształtuje się wcześniej od piekła teologicznego. Ponieważ wspiera się raczej na imaginacji niż na rozumie, jego rozwój postępuje zgodnie z ewolucją wyobrażeń i potrzeb zbiorowych. Nie dba ono o dogmaty i asymiluje wielorakie elementy zarówno z mitologii i wierzeń pogańskich, jak z chrystianizmu. Natomiast piekło teologiczne poczyna tu sobie rozważniej. [...] Teolodzy pogardzają piekłem ludowym i prawie o nim nie wspominaja. Święty Tomasz z Akwinu stwierdza krótko, że wszystko, co się mówi o piekle, należy rozumieć symbolicznie"'

Tymczasem Peregryn z Opola, wykształcony przecież dominikanin, materializuje piekło dość nonszalancko, bo zaraz pod powierzchnią gruntu: „,Kiedy bowiem [Maciej Apostoł] wyszedł z więzienia i głosił słowo Boże, a niektórzy szydzili z niego, ziemia się otwarła i wielu pochłonęła, tak że żywi wpadli do piekła (vivi ad infernum descenderunt ${ }^{10}$ )" [S 18]. Tu widzimy, że przy odrobinie pecha można do niego wpaść. Jedno z egzemplów ukazuje scenę, $w$ której diabeł prowadził pewnego człowieka „W stronę jakiegoś dołu (unam fossam), gdzie kiedyś było źródło (fuerat fons), i zepchnął go tam. W ten sposób zaprowadził go do piekła [...]" [T 10]. W innym

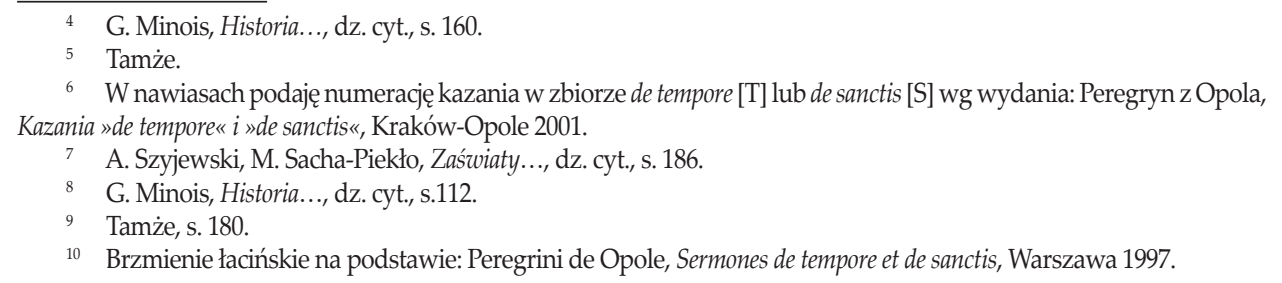


miejscu mowa o jaskini piekielnej (spelunca inferni) [T 61], co jeszcze bardziej podkreśla łatwość dostępu. Nie brak też odwołania do obu najpopularniejszych wędrówek przed Boską Komedią : w kazaniu Na święto Obrzezania Pana [T 8] możemy towarzyszyć św. Patrykowi w przemierzaniu zaświatów, zaś kazanie Na dwudziesta piąta niedzielę po Zestaniu Ducha Świętego [T 64] prezentuje Tundala (Tundalus) przyglądającego się cierpiącym duszom. Z pewnością więc piekło Peregryna nie należy do odizolowanych. Przeciwnie: wydaje się, że jego bliskość jest specjalnie wyeksponowana, a jego granice ulegają zatarciu.

W tej sytuacji nie trudno o kuriozum, o niepożądaną trywialność, jak w egzemplum, w którym „pewien mieszczanin, który pościł rzadko, a nawet nie chciał pościć wcale, tylko bez przerwy żył w rozkoszach, wracał jednego razu nocą z wielkiego pijaństwa całkiem zamroczony do swojego domu. Diabeł, schwytawszy go, zepchnął do studni (in unum fontem), która znajdowała się na ulicy. Kiedy nastał ranek znaleziono go w studni, a duszę - jak się obawiam (ut timeo) - w piekle". Zauważyliśmy tu wahanie, ale kaznodzieja natychmiast dodaje: „Wyjawił to pewien opętany przez czarta (obsessus homo manifestavit). Godzien jest więc potępienia ten człowiek [T 55]". Fakty przedstawiaja się następująco: amator alkoholu (totus ebrius), kończy spacer po omacku (in nocte), na dnie studni. Wypadek tego mieszczanina i połączenie go z wejściem do piekła może budzić pewne wątpliwości. Te zaś ma rozwiać rodzaj medium, za które w średniowieczu uchodzi opętany, ale trywialność nieszczęśliwego zdarzenia podważa potrzebę dodatkowych wyjaśnień. Wszystko wydaje się doskonale zrozumiałe, a w dodatku widzimy nawet wahanie samego kaznodziei. Działanie sił piekielnych wydaje się tu nie tylko zbędne, ale nie przynosi elementu zaskoczenia. Poza tym pod koniec XIII wieku audytorium powinno być już raczej przyzwyczajone do takiej retoryki.

Czy jednak nie popełnia się w ten sposób błędu anachronizmu? błędnego uwspółcześniania mentalności odbiorców? Otóż odpowiedzi należy szukać, kierując się w dwie strony.

Po pierwsze: wychodząc poza kazania Peregryna z Opola. Przywołajmy jeszcze raz dzieło Georgesa Minoisa: „Począwszy od wieku XI, a zwłaszcza w ciągu XII, dokonuje się ostatecznie proces pełnego zintegrowania kultury i piekła, dotychczas znajdującego sięjakby w zawieszeniu pomiędzy folklorem a myślą teologiczną. Zasymilowane zarówno przez elitę, jak i masy ludu chrześcijańskiego, wpisuje się ono w struktury mentalne, tak zbiorowe, jak i indywidualne, stając się ich trwałym komponentem. I ulega banalizacji" ${ }^{\prime \prime 2}$. W opinii tego badacza zjawisko banalizacji piekła jest tożsame ze sprowadzeniem go do rzeczywistości materialnej, nadaniem mu cech podpatrzonych w naturze i życiu społecznym, przez co staje się ono dla wszystkich zrozumiałe i w jakimś sensie bliskie, w przeciwieństwie do trudnych w odbiorze konstrukcji symbolicznych. Niesie to za sobą jednak niebezpieczeństwo przesady i sceptycyzmu. Źródła czasem przynoszą informację na temat obecności takich niedowiarków w społeczności średniowiecznej ${ }^{13}$.

Po drugie: same kazania Peregryna zawierają dowód takiego sceptycyzmu. W jednym z egzemplów kaznodzieja ukazał pewnego księcia, którego żona chce nakłonić na spowiedź przypomnieniem piekła. Książę jednak stwierdza: „Ty myślisz, że piekło jest? Przecież wymyślili je kaznodzieje, ażeby budzić w nas lęk". Łatwo zgadnąć, że po tej wypowiedzi dalszy los księcia musi być jak najgorszy; i rzeczywiście: w późniejszym czasie znajdowane są jego zwęglone zwłoki oraz list trzymany w ręku, który głosi: „Już przekonałem się, że piekło jest” [...][T 56].

Wbrew pozorom ta historyjka ma wiele wspólnego z poprzednią. W obu dochodzi do kolizji z systemem forsowanym przez Kościół, czego skutkiem jest grzech. W pierwszym przypadku

11 G. Minois, Historia ..., dz. cyt., s. 165-168.

12 Tamże, s. 156.

13 Tamże, s. 161. 
jest to grzech opilstwa (ebrietas), klasyfikowany w trzynastowiecznych egzemplach jako grzech łakomstwa (gula $)^{14}$. W drugim przypadku jest to szyderstwo z nauk Kościoła, co traktowano „jako szczególny rodzaj grzechu języka, podobny do bluźnierstwa"15 (blasphemia). W obu fabułach następuje szybka i skuteczna interwencja świata demonicznego w celu ukarania winnych. Zwróćmy też uwagę na medium (relacja opętanego oraz list). Pojawia się ono, aby odsłonić przed nami zaświaty. Bez niego każda z tych historii byłaby być może zagadkowym, ale jednak tylko śmiertelnym wypadkiem. Natomiast medium nadaje wyższy sens zdarzeniom, tworząc zarazem doskonale czytelną instrukcję: jest śmierć, bo był grzech. W tak uporządkowanym świecie nie ma miejsca ani na zaskoczenie, ani na przestrach powodowany niekontrolowanym zaburzeniem panujących zasad. Tylko pozornie ingerencja sił nadprzyrodzonych tworzy chaos, podczas gdy w rzeczywistości mamy do czynienia z konsekwentnie przestrzeganym porządkiem.

Osobny problem stanowi zły duch, który pojawił się w obu omawianych fabułach. W obrębie całości kazań Peregryn najczęściej określa go mianem dæmon lub diabolus. W arsenale tej postaci znajdują się trzy symboliczne pociski: śmierć doczesna, śmierć wieczna, czyli zesłanie do piekła i, najgorsza z nich wszystkich, odłączenie od Boga [T 4 $]^{16}$. Jednocześnie ostatnia z tych kar najmniej przemawiała do wyobraźni audytorium o czym świadczą zapewnienia w rodzaju: „Tego Baranka pragną oglądać i sami aniołowie. Tego Baranka pragnęli oglądać święci ojcowie [...]" [S 8]. Za to dużo wyraźniej prezentował się repertuar męczarni czekający na tych, którzy trafili do diabelskiego podziemia, czy - jak to określa kaznodzieja - zostali wyrzuceni na cmentarz piekielny (in cimiterium inferni) [T 4].

Dominującą tam karą jest zapowiadany w Ewangeliach "ogień nieugaszony" (Mk 9, 43-49) ${ }^{17}$. W jego sprawie zabierali głos tak wybitni teolodzy jak: Klemens Aleksandryjski, Orygenes, Grzegorz z Nyssy, czy Hieronim. Początkowo interpretowano go w duchu metaforycznym jako palące wyrzuty sumienia, a zatem cierpienia duchowe ${ }^{18}$. Natomiast do zmiany i uznania jego fizycznego wymiaru najprawdopodobniej przyczynił się autorytet Augustyna, który tak właśnie postrzegał tę kwestię.

Peregryn z Opola z pewną dbałością stara się przybliżyć nadzwyczajny charakter tej kary, pisząc, że „,gdyby fale morskie przelały się przez piekło, nie mogłyby ugasić jednej iskry" [T 31]. Tłumaczy też, że „ten, kto nie widzi oczyma serca, jak ciężko będzie z wyschniętym językiem cierpieć wieczne pragnienie, powinien iść w czasie wielkiego upału przez cały dzień bez picia, a wówczas poznałby dobrze, jakie to cierpienie. Również ten, kto nie widzi, jak trudno byłoby przejść z wody do zbytniego gorąca, powinien włożyć stopę do zimnej wody, kiedy jest bardzo zimno. Podobnie ten, kto nie widzi, jak ciężko będzie przebywać wiecznie w ogniu, powinien włożyć palec na godzinę do ognia" [T 17]. Jeszcze bardziej naturę ognia ma przybliżyć scenka z żywota świętego Makarego, „,który znalazł na pustyni głowę jakiegoś zmarłego człowieka i zaklinał ja, ażeby mu powiedziała, od kogo pochodzi. I powiedziała mu, że była głową jednego poganina. A święty Makary rzekł: »Gdzież jest twoja dusza?« Głowa odpowiedziała: »W piekle. Jest tam pod nami ogień tak głęboko, jak daleko jest od nieba do ziemi«. Makary zapytał: »Czy są tacy, którzy znajdują się poniżej was?« Odpowiedziała mu: »Pod nami są źli chrześcijanie, którzy przyjęli wiarę chrześcijańska, ale nie służyli Chrystusowi dobrymi uczynkami. Oni płona,

14 Por. W. Brojer, Diabet w wyobraźni średniowiecznej. Trzynastowieczne exempla kaznodziejkkie, Wrocław 2003, s. 192.

15 Tamże, s. 283.

16 Zob. powtórzenie tego motywu: T 46.

Mt 25; 41: „ogień wieczny"; Łk 16, 23-24: „płomien”".

G. Minois, Historia..., dz. cyt., s. 100-101. 
w większym ogniu niż my«". Zrazu wydaje się, że osobliwe cechy tych płomieni podważają reguły obowiązujące w świecie doczesnym, ale kaznodzieja wyjaśnia, „że chrześcijanie płoną $\mathrm{w}$ piekle $\mathrm{w}$ większym ogniu niż inni niewierni ludzie, bowiem ciała namaszczone mocniej goreją niż nienamaszczone. A chrześcijanie zostali namaszczeni olejami i krzyżmem, dlatego boleśniej odczuwają skutki ognia" [S58]. Nagle okazuje się, że niezwykła natura piekielnego ognia ma coś w sobie ze zwykłego płomienia, który wchodzi w reakcję z łatwopalnymi cieczami.

Równie swojsko prezentują się dodatkowe męczarnie, $\mathrm{w}$ których bierze udział diabeł $\mathrm{z}$ towarzyszami. „I tak ktoś widział - powiada kaznodzieja - że w piekle szatani wziąwszy tysiąc sto dusz na rozpalone kowadło uderzali w nie młotami, formując z nich jedną kulę, którą następnie wrzucili do ognia" [S 18]. Oprócz kuźni pojawiają się dodatkowe etaty dla demonów. Jeden z pieców obsługiwany jest przez węże, które wciagają grzeszników do jego środka [T 22]. W innym miejscu spotkać można rycerza siedzącego na koniu i trzymającego sokoła, przy czym zwierzęta te są demonami karzącymi miłośników polowań, dlatego koń stoi w płomieniach, a sokół rozrywa rycerzowi rękę [T 41]. W jeszcze innym miejscu dręczeni są hazardziści, którzy muszą grać ze złymi duchami w kości i szachy.

W tych mikroscenkach uderza trywialność, rozczarowujący brak wyszukania, co osiaga pewien pułap w przytoczonej przez kaznodzieję historii o człowieku, który „zabrał wdowie krowę, jedyną żywicielkę wdowy i jej dzieci. Kiedy zaś wdowa błagała ze łzami, by oddał jej krowę, odpowiedział: »eżeli ja nie zabiorę ci tej krowy, uczyni to ktoś inny«. I stało się, że ów człowiek wkrótce umarł i został wtrącony do piekła, i zamieniony, jak mu się wydawało, w krowę. Kiedy cierpiał tam różne męki, szczególnie jeden diabeł pod postacią krowy bardzo mu dokuczał (infestavit eum), nawet wówczas, gdy inne diabły dawały mu spokój. A gdy żadną miarą nie chciał zaprzestać, potępiony zapytał: »Dlaczego ty znęcasz się nade mną bardziej niż inni?« A diabeł odpowiedział: »Gdybym ja tego nie robił, czyniłby to ktoś inny«.

Ewidentnie w tym piekle rządzi zasada odpłaty. Każdy grzesznik potraktowany jest indywidualnie; do winy dopasowana zostaje kara. Na pierwszy rzut oka piekło sprawia wrażenie kipiącego chaosu, tymczasem wszystko jest w nim doskonale uporządkowane. Grzesznicy są oddzieleni od siebie nieprzekraczalnymi granicami, co widzimy na przykładzie złych chrześcijan, o których już była mowa, oraz nieochrzczonych dzieci, dla których „przeznaczone jest miejsce tam, gdzie przebywali w otchłani święci ojcowie przed męką Pana" [S54]. W tak zorganizowanej kaźni diabeł nie jest straszny, bo wykonuje tylko ściśle przypisane mu zadanie. Jednocześnie nawet krótkie zajrzenie do wnętrza piekła uderza brutalnością. Świadomie lub nie, ale kaznodzieje w rodzaju Peregryna z Opola realizują w ten sposób wytyczne pozostawione przez św. Hieronima, głoszącego, że nie należy przybliżać idei alegorycznych prostemu ludowi, bo łatwiej go zmotywować strachem ${ }^{19}$. To z kolei wiąże się z koniecznością zastosowania odwołań do prostych skojarzeń i pospolitego doświadczenia. Jednakże tak skonstruowany system nauczania prowadzi do trywializacji zarówno piekła jak i diabła sprowadzonego tam do poziomu narzędzia.

Nieco inaczej wygląda diabeł działający wśród żywych. W takim przypadku przyjmuje on ludzką postać i chętnie nawiązuje kontakt. Główną jego bronią jest język, ale nie jest mistrzem w tej dziedzinie. Zdarza mu się być nieskutecznym [np. S 52]. Mimo to chętnie się targuje lub paktuje jak w opowieści o świętym Dominiku, który podążał „by wypełnić obowiązek głoszenia słowa Bożego". Wówczas „zabiegł mu drogę szatan, mówiąc: »Co zamierzasz, Dominiku?« »Chcę głosić słowo Boże« - odpowiedział. Diabeł rzekł: »Obiecaj mi, że już nigdy ani ty, ani twoi

\footnotetext{
19 Tamże, s. 104.
} 
bracia nie będziecie głosili słowa Bożego, a ja ci przyrzeknę, że nigdy nie będę wystawiał na pokusy ciebie ani twoich braci i nikt nie wystąpi z twojego zakonu. «Święty Dominik zapytał: »Dlaczego chcesz to uczynić? Cóż ci szkodzi nasze kaznodziejstwo? « Diabeł odpowiedział: »Wiele dusz odbieracie mnie i moim towarzyszom! « (mihi et sociis meis aufertis). Dominik odpowiedział: »Ani ja nie poniecham głoszenia słowa Bożego, ani moi bracia. Ty kuś, a oni z pomocą Bożą będą skutecznie stawiać ci opór!«" [S 31]. Ta fabuła jest symptomatyczna: zazwyczaj diabeł namawia do działania, a tu do jego poniechania.

Spójrzmy na jeszcze jedną historię: „Pewien złodziej miał umowę z szatanem, że będzie mu służył, byleby tylko szczęściło mu się w złodziejskim rzemiośle. Diabeł przyobiecał mu to mówiąc, że w razie schwytania uwolni go i nie dopuści do stracenia na szubienicy. Kiedy złodziej nakradł już wiele, został $w$ końcu przyłapany na kradzieży i wtrącony do więzienia. Wtedy przyszedł do niego diabeł mówiąc: »Nie bój się! Nie powieszą cię, albowiem uczynię tak, że nie będzie można znaleźć w mieście żadnego sznura. Wtedy ty weź te pieniądze i daj sędziemu. W ten sposób wymkniesz się im«. Kiedy złodziej chciał tak zrobić, wyciagnną sznur zamiast pieniędzy i został powieszony" [T 46]. Widzimy jak diabeł bezlitośnie wykorzystał okoliczności. Chwila, w której złodziej znajduje się w matni, staje się decydująca.

Wykorzystywanie ludzkiej słabości lub czyhanie na moment odsłonięcia się to cecha charakterystyczna diabła. Złe duchy w omawianych kazaniach mają być podobne do rozbójników: „Rozbójnicy bowiem zwykli śledzić kupców. Wiedząc, że wiozą oni ze sobą cenne skarby, chcą ich w dogodnym momencie ograbić" [T 53]. Adekwatnie do tego diabeł topi pijanych [T 64; T 55], pojawia się przy łożu chorych [T 50], czai się w leśnych okolicach [T 54], nawiedza wyposzczonych eremitów [T 60] oraz potrzebujących, którzy go wzywają [T 61]. Co ciekawe, wszystko to robić ma z powodu własnej niemocy: „diabeł wydaje się najpotężniejszy pod niebem, a jednak nie ma śmiałości wyrwać nam nawet jednego włosa" [T 55]. W dodatku Peregryn robi z niego wręcz niezdarnego seniora, gdy pisze: „zaiste, jest starcem, ponieważ ma już 6220 lat! Pozbawiony zaś rozumu jest dlatego, ponieważ rozpalił tyle ognisk, ile dusz zamierza sprowadzić do piekła. Jego niegodziwość przejawia się w tym, że chociaż wie, iż mu się to udaje, nie przestaje kusić ludzi" [T 30].

W kazaniach Peregryna z Opola możemy wyodrębnić więc dwa portrety diabła. Jeden ukazuje istotę antropomorficzna, która przyjmuje ludzkie sposoby zachowań, zwłaszcza te negatywne, upodabniając się do grzeszników i żyjąc pośród nich. Kazanie Na szósta niedzielę po Zestaniu Ducha Świętego zawiera kluczową tutaj frazę: „,naszym bratem jest również szatan, ponieważ mamy tego samego Stwórcę". Tak brzmi teologiczne uzasadnienie człekokształtnego portretu diabła. Komplikuje to jednak jego rzekomą funkcję straszaka. Trudno mówić o przerażeniu skoro widzimy go w ludzkiej skórze. Na dodatek ma być z nami spokrewniony, co zmienia go niemalże $\mathrm{w}$ istotę oswojoną. Natomiast nie zawiesza to jego misji i współdziałania $\mathrm{z}$ diabłem z piekieł, którego możemy ująć w drugi portret. Przedstawia on bezwzględnego, ale zdyscyplinowanego okrutnika. Nie opuszcza on kaźni, bo ma pełnić przecież wytyczone tam zadania. Dlatego nie wydaje się groźny dla żywych.

Na tym tle Peregryn z Opola, mimo że jego kazania przesycone są krwawymi skłonnościami wyobraźni ludowej, nie może znaleźć się w kręgu duszpasterzy strachu. Jego piekło i oba portrety demonicznego bohatera nie przerażaja, lecz nadają sens „fatalnym zdarzeniom" w życiu doczesnym oraz ewentualnie realizują ideę rewanżyzmu, gdzie zły musi źle skończyć. Nie ma więc racji Georges Minois, który w XIII wieku widział eskalację koszmarnych wizji. Trafniejsza wydaje się tu ocena innego znawcy tematu, Wojciecha Brojera, który pisze: „Trzynastowieczni kaznodzieje pozwalają swoim słuchaczom (i sobie samym) »cośkolwiek zobaczyć«. Straszny 
diabeł i okrutne piekło - poza wszystkim - mają moc katharsis, wyzwalają człowieka od strachu przed niezrozumiałym światem"20. Tak więc można zaryzykować, że diabeł w kazaniach Peregryna z Opola jest elementem dyscyplinującym, ale w żadnym razie jego postać nie podważa ufności w boski porządek a raczej go podkreśla.

\section{LITERATURA PODMIOTU}

Peregrini de Opole, Sermones de tempore et de sanctis, Warszawa 1997.

Peregryn z Opola, Kazania »de tempore« $i$ »de sanctis«, Kraków-Opole 2001.

\section{LITERATURA PRZEDMIOTU}

Brojer W., Diabeł w wyobraźni średniowiecznej. Trzynastowieczne exempla kaznodziejkkie, Wrocław 2003.

Delumeau J., Strach w kulturze Zachodu. XIV-XVIII w., Warszawa 1986.

Minois G., Historia piekła, Warszawa 1996.

Szyjewski A., Sacha-Piekło M., Piekło, [w:] Sacha-Piekło M. (red.), Zaświaty i krainy mityczne. Leksykon, Kraków 1999.

\section{Słowa kluczowe}

Peregryn z Opola, egzempla, George Minois, Jean Delumeau, kazania, średniowiecze, nowa ewangelizacja, duszpasterstwo strachu, wizja zaświatów, piekło, szatan, diabeł

\section{STRESZCZenie}

Powstałe u schyłku XIII w. kazania Peregryna z Opola należą nie tylko do narzędzi „nowej ewangelizacji", której dokonywały w tym stuleciu zakony żebracze, ale są również jednymi z najpopularniejszych w całej Europie, aż do wieku XVI. Z tego względu można je uznać za dość reprezentatywne dla nauczania z końca Średniowiecza.

W ich świetle ciekawie przedstawiają się poruszające problem demonologii prace dwóch sławnych historyków kultury: Georgesa Minoisa i Jeana Delumeau'a. Pierwszy z tych uczonych jest zdania, że około $1250 \mathrm{r}$. nastąpiło teoretyczne usystematyzowanie zjawiska zwanego duszpasterstwem strachu, które polegało na poprawie moralności wiernych metodą przerażania wizjami zaświatów. Tymczasem Jean Delumeau jest zupełnie innego zdania. Uważa on, że nastąpiło to zdecydowanie później, a symbolicznym słupem granicznym początku nadpływającej fali satanizmu jest Boska komedia (której autor zmarł w 1321 r.). Delumeau uważa, że to dopiero od XIV wieku, a więc u progu Renesansu, następuje powolna, ale sukcesywna „demoniczna inwazja", która minie z wolna dopiero w XVII stuleciu.

Celem artykułu jest skonfrontowanie tych sprzecznych opinii z kazaniami Peregryna z Opola przy jednoczesnym wydobyciu demonologii tego kaznodziei. Szczególnie bowiem na uwagę zasługują tu jego egzempla, w których stosunkowo często zostaje przywołana wizja zaświatów, w tym również piekła. Równie często w kazaniach pojawia się postać demoniczna. Analiza tych rozproszonych wzmianek uwidacznia, że diabeł, szatan, czy zły duch, jeśli znajduje się u siebie $\mathrm{w}$ piekle, jest okrutnym siepaczem, ale zarazem jest ograniczony pilnowaniem adekwatności kary do czynu. Z kolei zaś, gdy znajduje się pośród ludzi, stara się do nich upodobnić i czyha jedynie na ich błąd, sam będąc ograniczonym w działaniach. Taka postać złego jest więc tylko karzącym ramieniem sprawiedliwości w czym uwidacznia się uporządkowana wizja świata, inna od tej, którą opisywał Georges Minois.

20 W. Brojer, Diabet..., dz. cyt., s. 608. 


\section{The devil in the Sermons of Peregrinus Opoliensis}

\section{Keywords}

Peregrinus Opoliensis, exempla, George Minois, Jean Delumeau, sermons, Middle Ages, new evangelisation, the preaching of fear, vision of the beyond, hell, Satan, devil

\section{Summary}

Created at the end of the $13^{\text {th }}$ century the sermons of Peregrinus Opoliensis are not only tools of the "new evangelisation", which had been conducted in that century by the mendicant orders, but are also some of the most popular in the whole Europe, until the $16^{\text {th }}$ century. And because of this, they can be considered as representative for the teachings of the late Middle Ages.

In this context the works of two famous historians of culture: George Minois and Jean Delumeau, discussing the problem of demonology, are especially interesting. The former of the academics claims that about the year of 1250 took place the theoretic systematisation of the phenomenon called "preaching of fear", which was the improvement of the morality of the faithful with the method of terrifying them with the vision of the beyond. Yet Jean Delumeau's claims are completely different. He states that it is not before the $14^{\text {th }}$ century that everything changes and that it is then that the repression of the diabolic matters, which was succeeded by the classical age of cathedrals, makes way for the progressive demonic invasion. The Divine Comedy (which's author died in 1321) marks the symbolic transformation from one age to another and the moment when the religious awareness of the western elite begins to cease to resist the wave of Satanism. It would recover not before the $17^{\text {th }}$ century.

The aim of the paper is the confrontation of those contradictory opinions with the sermons of Peregrinus Opoliensis along with simultaneous extraction of the preacher's demonology. His exempla demand special attention, as in them often the vision of the beyond, including hell, is relatively often summoned. Equally often the demonic figure appears in the sermons. The analysis of those scattered mentions reveals that the devil, Satan, or evil spirit, if present in his hell, is a cruel executioner, however he is also limited by the guarding of the adequacy of the punishment to the deed. But when he is among the people, he attempts to become similar to them and lurks for their mistakes, being himself limited in his actions. Such a figure of the evil one is thus only a punishing arm of justice, through which an organised vision of the world is revealed, distinct from the one, which has been describes by George Minois. 